\title{
Incidence Rates, Pattern and Time Trends of Registered Cancer in Iraq (1991-2008) Population and Hospital Based Registry
}

\author{
Hamid Yahya Husain1, Sharif F. A. Al-Alawachi² \\ ${ }^{1}$ Faculty of Medicine, University of Baghdad, Baghdad, Iraq \\ ${ }^{2}$ Merjan Teaching Hospital Oncology Cancer Center, Babylon Health Directorate, Babylon, Babylonia \\ Email: hussainh569@gmail.com
}

Received 13 December 2013; revised 25 January 2014; accepted 5 February 2014

Copyright (C) 2014 by authors and OALib.

This work is licensed under the Creative Commons Attribution International License (CC BY). http://creativecommons.org/licenses/by/4.0/

(c) (i) Open Access

\section{Abstract}

Background: Global cancer rates have been increasing primarily due to many reasons: an aging population and lifestyle changes in the developing world were major causes. In 2008, approximately 12.7 million cancers were diagnosed and 7.6 million people died of cancer worldwide. Objectives: To study the epidemiological patterns of the top 10 registered cancers over the years of 1991-2008 in Iraq. To identify the socio-demographic characteristics and determinants of cancers in Iraq and to identify time trends. Results: The study revealed that the number of cancer cases registered was 5720 in Iraq (31.05) per 100,000 in 1991 to 14,180 (44.46) per 100,000 population in 2008. While age incidence of cancer in Iraq increased with age, starting from almost 7 cases per 100,000 population at age below 10 years to 398 cases per 100,000 population at age 70 years old, the top 10 cancer incidence in Iraq was breast cancer followed by lung cancer, leukemia, bladder cancer, brain and CNS, non Hodgkin's lymphoma, colo-rectal cancer, stomach cancer, skin cancer excluding melanoma, larynx cancer. Cancer incidence rate significantly increases after 2000 (mean incidence was around 55 cases per 100,000 population) in comparison with the period before 2000 (mean incidence was 40 cases per 100,000 population). The highest age incidence rate is the age of 70 years of $(397$ per 100,000) followed by $65+$ years $(327$ cases per 100,000 population). Conclusion: Cancer incidence in Iraq is relatively high and trends are up going in terms of quantity and variables related like age sex etc. The figures reflect little increment due to population growth. Prevention and management of cancer are still inadequate. Recommendations: Strengthening the national cancer prevention, cancer therapeutic and cancer registry program to improve cancer related outcomes; addressing effective interventional strategies in terms of risk management, life style promotion and hazardous exposure through establishing national health related multistakholders projects. 


\section{Keywords}

\section{Incidence Rate; Pattern; Cancer; Iraq}

\section{Introduction}

Global cancer rates have been increasing primarily due to many reasons like aging population and lifestyle changes in the developing world [1]. The most significant risk factor for developing cancer is the age [2]. Although it is possible for cancer to strike at any age, most people who are diagnosed with invasive cancer are over the age of 65 [2] [3]. Some of the association between aging and cancer is attributed to immune-deterioration [4], errors accumulated in DNA over a lifetime [5], and age-related changes in the endocrine system [6].

In 2008, approximately 12.7 million cancers were diagnosed (excluding non-melanoma skin cancers and other non-invasive cancers) and 7.6 million people died of cancer worldwide [1]. Cancers as a group account for approximately $13 \%$ of all deaths each year with the most common being: lung cancer (1.4 million deaths), stomach cancer (740,000 deaths), liver cancer (700,000 deaths), colorectal cancer (610,000 deaths), and breast cancer (460,000 deaths) [7]. This makes invasive cancer the leading cause of death in the developed world and the second leading cause of death in the developing world [1]. Over half of cases occur in the developing world [1]. The three most common childhood cancers are leukemia (34\%), brain tumors (23\%), and lymphomas (12\%) [7]. Rates of childhood cancer have increased by $0.6 \%$ per year between 1975 to 2002 in the United States [8] and by 1.1\% per year between 1978 and 1997 in Europe [7]. In 2007, the overall cost of cancer in the US-including treatment and indirect mortality expenses (such as lost productivity in the workplace) — was estimated to be $\$ 226.8$ billion. In 2009, 32\% of Hispanics and 10\% of children 17 years old or younger lacked health insurance; uninsured patients and those from ethnic minorities are substantially more likely to be diagnosed with cancer at a later stage, when treatment can be more extensive and more costly [9].

Study objectives:

- To study the patterns of the top 10 registered cancers over the last 20 years in Babylon and middle Euphrates governorate in middle part of Iraq in relation to socio-demographic characteristics.

- To study the time trends of cancer incidence for the top 10 registered cancers in Babylon and middle Euphrates governorate/middle of Iraq

Population and methods:

Retrospective records review the incidence data from the population and hospital-based Cancer Registry of Iraq and Cancer registry at Iraqi Cancer registry (Iraqi council for cancer registration/MOH/Baghdad). Data of cancer cases and deaths obtained from the Official State Database for the period 1990-2008 were used. Incidences were calculated. Time trends were obtained. 196,304 registered cases were interpreted: 99,831 were males and 96,304 were females.

\section{Results}

The study revealed that in Figure 1 the number of cancer cases registered was 5720 cancer in Iraq (31.05) case per 100,000 in 1991 to 14,180 case (44.46) per 100,000 population 2008 while Figure 2 revealed that age incidence of cancer in Iraq is increasing with older age group starting from almost 7 case per 100,000 population at age below 10 raising to 398 case per 100,000 population at age group 70 years old. Table 1 showed that cancer incidence rate significantly increase for the years after 2000 (Mean incidence was (around 55 case per 100,000 population in comparison with the period before 2000 (mean incidence was (40 case per 100,000 population) and the number of cancer case registered was 5720 cancer in Iraq (31.05) case per 100,000 in 1991 to 14,180 case (44.46) per 100,000 population 2008. Table 2 and Figure 2 revealed that the $t$ age incidence rate is the age of 70 years of (397 per 100,000) followed by 65+ (327 cases per 100,000 populations), Table 3 Estimated Population of Iraqi by age and gender 2008 while Table 4 revealed the top 10 cancer incidence in Iraq which was breast cancer followed by lung cancer, leukemia, bladder cancer, brain and CNS, non Hodgkin's lymphoma, colo-rectal cancer, stomach cancer, skin cancer excluding melanoma, larynx cancer. 


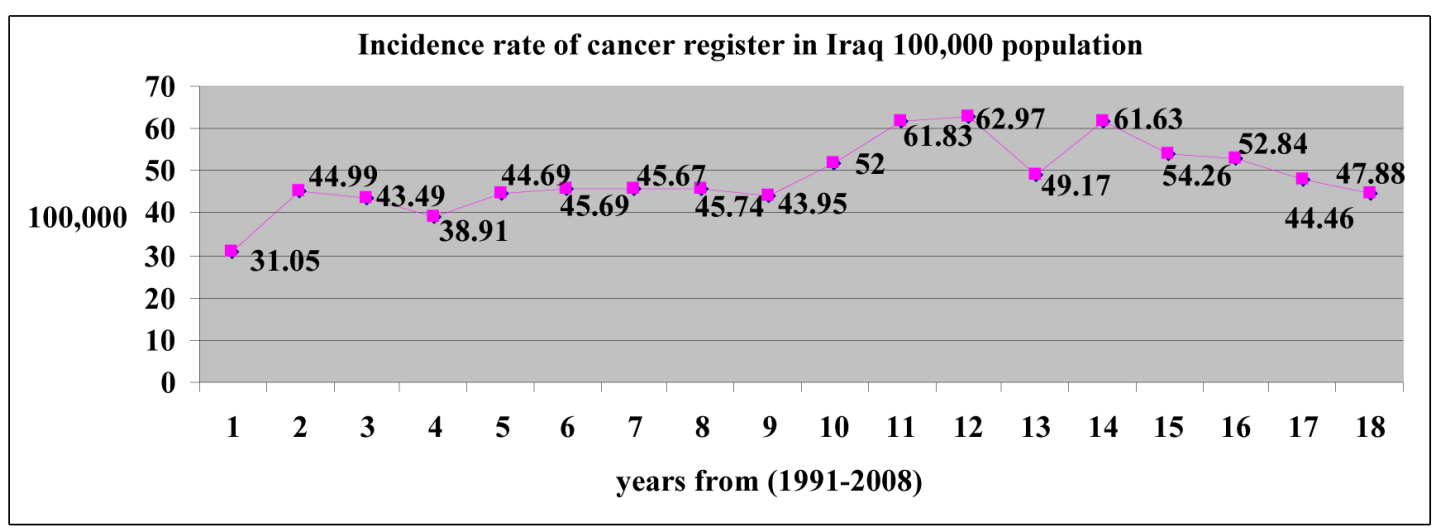

Figure 1. Incidence rate registered in Iraq (1991-2008).

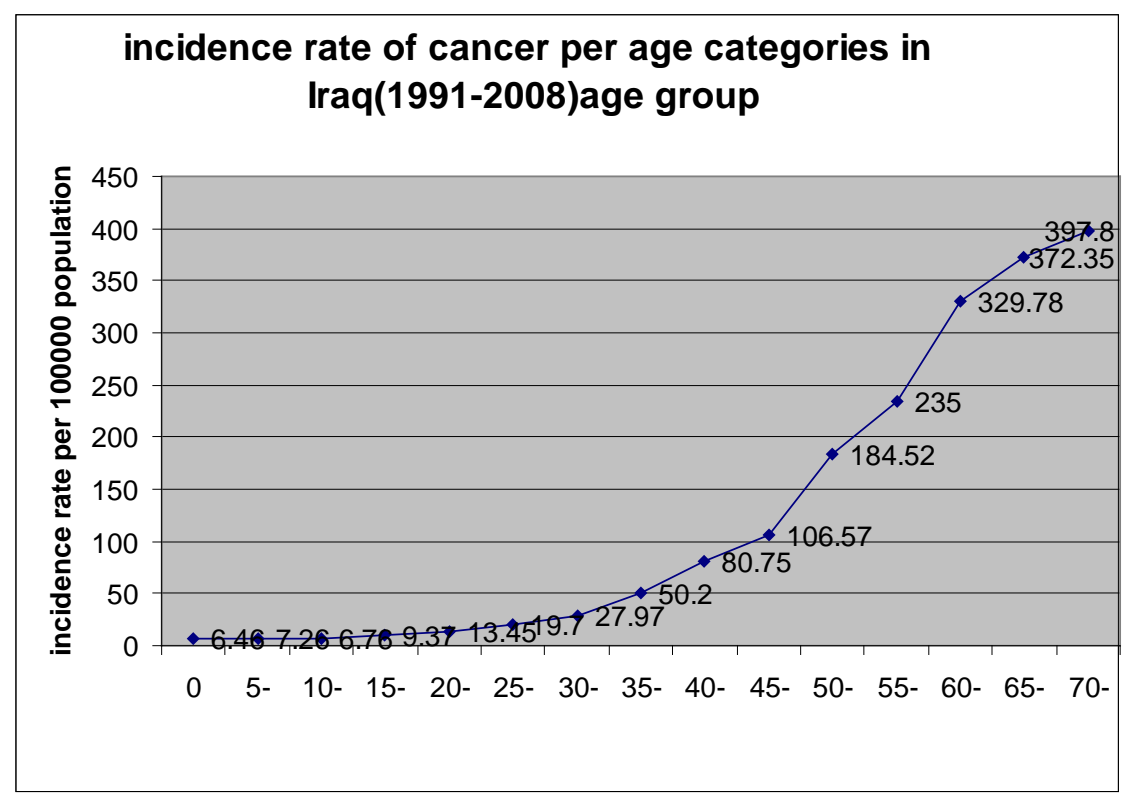

Figure 2. Incidence rate of cancer per age categories in Iraq (1990-2008).

\section{Discussions}

The study showed that the number of new cases registered was razing from 5720 in 1991 to 14,180 case on 2008 which is equal almost to three times increment of cancers in Iraq increased from 83 cases per 100,000 population in 1990 to 996 per 100,000 population in 2011 and this result is similar with the result of (Crocetti E., 2002) [10] which showed increase of cancer incidence and mortality in Italy/Florence [11] [12], this result can be explained by increase exposure to risk factors specially life style one as well as good cancer registry services.

Over all figures of Cancer incidence in Iraq showed more prevalence among.

Male than females from 1991 up to 2000 then equal male female distribution with slightly increase registered female incidence than male which is similar to a study carried out in Sweden [13] (Li, X.; Mutanen, P.; Hemminki, K., 2001), yet better registry for breast and cervical cancers due to applying public health screening programs become more predominant after the year 20,000 which make the overall prevalence more among females in comparison male in spite of lung cancer is significantly reported among males in Iraq.

As for the age trend, current study shows the highest incidence rate among the age group 65Y and above age groups which is similar of the results of a study carried out in Ireland (Irish Cancer Registry, 2006) [14]) that showed the highest incidence at the age group 74 - 84 which can be explained on the base of deteriorating immune status, aging of the cells and the chronic cytological irritation and degeneration among Iraqi population is 
H. Y. Husain, S. F. A. Al-Alawachi

Table 1. Cancer incidence registered in Iraq (1991-2008) based on gender.

\begin{tabular}{|c|c|c|c|c|c|c|}
\hline Year & NO of new cases register & Male NO & $\%$ & Female NO & $\%$ & Registered cases per 100,000 Population \\
\hline 1991 & 5720 & 3125 & 54.63 & 2595 & 45.37 & 31.05 \\
\hline 1992 & 8526 & 4735 & 55.54 & 3791 & 44.46 & 44.99 \\
\hline 1993 & 8471 & 4632 & 54.68 & 3839 & 45.32 & 43.49 \\
\hline 1994 & 7785 & 4230 & 54.34 & 3555 & 45.66 & 38.91 \\
\hline 1995 & 7947 & 4344 & 54.66 & 3604 & 45.34 & 44.69 \\
\hline 1996 & 8360 & 4466 & 53.42 & 3894 & 46.58 & 45.69 \\
\hline 1997 & 8592 & 4521 & 52.62 & 4071 & 47.38 & 45.67 \\
\hline 1998 & 9033 & 4774 & 52.85 & 4259 & 47.15 & 45.74 \\
\hline 1999 & 8936 & 4556 & 50.98 & 4380 & 49.02 & 43.95 \\
\hline 2000 & 10,888 & 5376 & 49.38 & 5512 & 50.63 & 52.00 \\
\hline 001 & 13,332 & 6758 & 50.69 & 5674 & 49.31 & 61.38 \\
\hline 002 & 13,985 & 6964 & 49.80 & 7021 & 50.20 & 62.97 \\
\hline 003 & 11,248 & 5698 & 50.66 & 5550 & 49.34 & 49.17 \\
\hline 004 & 14,520 & 7525 & 51.83 & 6995 & 48.17 & 61.63 \\
\hline 005 & 15,172 & 7505 & 49.47 & 7667 & 50.53 & 54.26 \\
\hline 006 & 15,226 & 7377 & 48.45 & 7849 & 51.54 & 52.84 \\
\hline 007 & 14,213 & 6656 & 46.83 & 7557 & 53.16 & 47.88 \\
\hline 008 & 14,180 & 6589 & 46.47 & 7591 & 53.53 & 44.46 \\
\hline Total & 196,135 & 99,831 & 50.90 & 96,304 & 49.10 & - \\
\hline
\end{tabular}

Table 2. Estimated Population of Iraqi by age and gender 2008.

\begin{tabular}{cccc}
\hline Age group & Male & Female & Total \\
\hline $0-4$ & $2,737,428$ & $2,602,122$ & $4,535,561$ \\
$5-9$ & $2,327,723$ & $2,207,838$ & $3,874,072$ \\
$10-14$ & $1,970,148$ & $1,903,924$ & $3,445,344$ \\
$15-19$ & $1,752,751$ & $1,692,593$ & $2,950,779$ \\
$20-24$ & $1,499,023$ & $1,451,756$ & $2,517,689$ \\
$25-29$ & $1,272,624$ & $1,245,065$ & $2,116,516$ \\
$30-34$ & $1,061,612$ & $1,054,904$ & $1,744,990$ \\
$35-39$ & 66,556 & 878,434 & $1,377,173$ \\
$40-44$ & 671,299 & 705,874 & $1,101,626$ \\
$45-49$ & 531,995 & 569,631 & 849,751 \\
$50-54$ & 407,517 & 442,234 & 657,450 \\
$55-59$ & 314,272 & 343,178 & 487,900 \\
$60-64$ & 234,608 & 253,292 & 350,481 \\
$65-69$ & 165,788 & 184,693 & 546,755 \\
$70+$ & 244,808 & 301,947 & $31,895,637$ \\
Total & $1,605,152$ & $15,837,485$ & \\
\hline
\end{tabular}


Table 3. Cancer age specific rate per 100,000 populations in Iraq 2008.

\begin{tabular}{|c|c|c|c|c|c|c|}
\hline Age group & Male No of cases & Incidence rate & Female No of cases & Incidence rate & Total NO of cases & Total Incidence rate \\
\hline $0-4$ & 194 & 7.09 & 151 & 5.80 & 345 & 6.46 \\
\hline $5-9$ & 199 & 8.55 & 130 & 5.89 & 320 & 7.25 \\
\hline $10-$ & 158 & 8.02 & 104 & 5.46 & 262 & 6.76 \\
\hline $15-$ & 175 & 9.9 & 148 & 8.74 & 323 & 9.37 \\
\hline $20-$ & 202 & 13.4 & 195 & 13.43 & 397 & 13.45 \\
\hline $25-$ & 205 & 16.11 & 291 & 23.37 & 496 & 19.70 \\
\hline $30-$ & 207 & 19.50 & 385 & 36.50 & 592 & 27.97 \\
\hline $35-$ & 295 & 34.04 & 581 & 66.14 & 876 & 50.20 \\
\hline $40-$ & 352 & 52.44 & 760 & 107.67 & 1112 & 80.75 \\
\hline $45-$ & 335 & 62.97 & 839 & 147.29 & 1174 & 106.57 \\
\hline $50-$ & 580 & 143.33 & 988 & 223.41 & 1568 & 184.52 \\
\hline $55-$ & 676 & 215.10 & 869 & 253.22 & 1545 & 235.00 \\
\hline $60-$ & 867 & 369.55 & 742 & 202.94 & 1609 & 320.78 \\
\hline $65-$ & 774 & 466.6 & 531 & 287.50 & 1305 & 372.35 \\
\hline $70-$ & 1331 & 543.69 & 844 & 279.52 & 2175 & 397.80 \\
\hline Unknown & 39 & - & 33 & - & 72 & - \\
\hline All & 6589 & 41.03 & 7591 & 47.93 & 14180 & 44.46 \\
\hline
\end{tabular}

Table 4. Commonest 10 cancers in Iraq 2008.

\begin{tabular}{cccccc}
\hline Cancer Site & No of cases & Male & Female & \% of Total & Rsegisterd case/100,000 population \\
\hline Breast cancer & 2729 & 92 & 2637 & 19.25 & 8.56 \\
Bronchus and lung & 1375 & 975 & 400 & 9.70 & 4.31 \\
Leukemia & 860 & 555 & 405 & 6.77 & 3.01 \\
Urinary Bladder & 881 & 667 & 214 & 6.21 & 2.76 \\
Brain \& other CNS & 780 & 406 & 374 & 5.50 & 2.24 \\
Colorectal cancer & 693 & 378 & 315 & 4.89 & 2.17 \\
stomach & 471 & 274 & 197 & 3.32 & 1.48 \\
Skin (excluding melanoma) & 367 & 215 & 152 & 2.59 & 1.15 \\
Larynx & 334 & 251 & 83 & 2.36 & 29.18 \\
Total 10 & 9306 & 4247 & 5059 & 65.63 & 44.465 \\
\hline All sits & 14,180 & 6589 & 7591 & 100.00 & \\
\hline
\end{tabular}

shorter than western and most of the cancers cases in Iraq I are younger age group [15] [16], this finding raise the issue of demographic characteristics of cancer in Iraq.

Has been identified by current study that the top 10 cancers in Iraq is as follow top 10 cancer incidence in Iraq which was breast cancer followed by lung cancer, leukemia, bladder cancer, brain and CNS, non Hodgkin's lymphoma, colo-rectal cancer, stomach cancer, skin cancer excluding melanoma, larynx cancer which is similar to many other studies in the region [17]. 


\section{Conclusion}

Cancer incidence in Iraq is relatively high and trends are up going in terms of quantity and variables related like age, sex, etc. Prevention and management of cancer are still inadequate.

\section{Recommendations}

Strengthening the national cancer prevention, cancer therapeutic and cancer registry program to improve cancer related outcomes.

Addressing effective interventional strategies in terms of risk management, life style promotion and hazardous exposure through establishing national health related multistakholders projects.

\section{Declaration}

Ethical standards were applied in the study. There is no conflict of interest and no fund received so far to carry out this research.

\section{References}

[1] Jemal, A., Bray, F., Center, M.M., Ferlay, J., Ward, E. and Forman, D. (2011) Global Cancer Statistics. CA: A Cancer Journal for Clinicians, 61, 69-90.

[2] Johnson, G. (2010) Unearthing Prehistoric Tumors, and Debate. The New York Times. http://www.nytimes.com/2010/12/28/health/28cancer.html

[3] Pawelec, G., Derhovanessian, E. and Larbi, A. (2010) Immunosenescence and Cancer. Critical Reviews in Oncology/Hematology, 75, 165-172. http://dx.doi.org/10.1016/j.critrevonc.2010.06.012

[4] Albert's, B., Johnson, A., Lewis, J., et al. (2002) The Preventable Causes of Cancer. Molecular Biology of the Cell. 4th Edition, Garland Science, New York.

[5] Anisimov, V.N., Sikora, E. and Pawelec, G. (2009) Relationships between Cancer and Aging: A Multilevel Approach. Biogerontology, 10, 323-338. http://dx.doi.org/10.1007/s10522-008-9209-8

[6] WHO Report on Cancer (2010). http://www.who.int/nmh/publications/ncd_report_chapter1.pdf?ua=1

[7] World Health Organization (2011) Cancer. http://www.who.int/mediacentre/factsheets/fs297/en/

[8] Kaatsch, P., Sikora, E. and Pawelec, G. (2010) Epidemiology of Childhood Cancer. Cancer Treatment Reviews, 36, 277-285. http://dx.doi.org/10.1016/j.ctrv.2010.02.003

[9] Ward, E.M., Thun, M.J., Hannan, L.M. and Jemal, A. (2006) Interpreting Cancer Trends. Annals of the New York Academy of Sciences, 1076, 29-53. http://journalistsresource.org/studies/society/health/cancer-facts-figures-2012/ http://dx.doi.org/10.1196/annals.1371.048

[10] Crocetti, E., Paci, E., Miccinesi, G., Costantini, A.S. and Zappa, M. (2002) Time Trends in Cancer Incidence and Mortality in Central Italy. European Journal of Cancer Prevention, 11, 387-395. http://dx.doi.org/10.1097/00008469-200208000-00011

[11] Kaatsch, P., Sikora, E. and Pawelec, G. (2010) Epidemiology of Childhood Cancer. Cancer Treatment Reviews, 36, 277-285. http://dx.doi.org/10.1016/j.ctrv.2010.02.003

[12] Ward, E.M., Thun, M.J., Hannan, L.M. and Jemal, A. (2006) Interpreting Cancer Trends. Annals of the New York Academy of Sciences, 1076, 29-53. http://dx.doi.org/10.1196/annals.1371.048

[13] Li, X. and Mutanen, P. (2001) Hemminki. European Journal of Cancer Prevention, 10, 227-235. http://dx.doi.org/10.1097/00008469-200106000-00005

[14] National Cancer Registry Irish (2006) Trends in Irish Cancer Incidence 1994-2002.

[15] Albert's, B., Johnson, A., Lewis, J., et al. (2002) The Preventable Causes of Cancer. Molecular Biology of the Cell. 4th Edition, Garland Science, New York.

[16] Coleman, W.B. and Rubinas, T.C. (2009) “4”. In: Tsongalis, G.J. and Coleman, W.L., Eds., Molecular Pathology: The Molecular Basis of Human Disease, Elsevier Academic Press, Amsterdam, 66.

[17] Janet, F. (2012) Spotlight on Top 5 Cancers in the Middle East Region (Talking Cancers in the Middle East. Cancer World Organization Cited). http://www.cancerworld.org/articles/issues_25/spotlight_on\%A7\%A7\%A7/tackling_cancer_in_the_middle_east.html 